\title{
Contrast and Critique of Two Approaches to Discourse Analysis: Conversation Analysis and Speech Act Theory
}

\author{
Nguyen Van Han \\ College of Finance and Customs \\ B2/1A 385 Street, Tang Nhon Phu A Ward, District 9, Ho Chi Minh City 70000, Vietnam \\ E-mail: nguyenvanhan@tchq.edu.vn
}

\author{
Doi:10.7575/aiac.alls.v.5n.4p.155 \\ URL: http://dx.doi.org/10.7575/aiac.alls.v.5n.4p.155
}

Received: $17 / 06 / 2014$

Accepted: 26/07/2014

\begin{abstract}
Discourse analysis, as Murcia and Olshtain (2000) assume, is a vast study of language in use that extends beyond sentence level, and it involves a more cognitive and social perspective on language use and communication exchanges. Holding a wide range of phenomena about language with society, culture and thought, discourse analysis contains various approaches: speech act, pragmatics, conversation analysis, variation analysis, and critical discourse analysis. Each approach works in its different domain to discourse. For one dimension, it shares the same assumptions or general problems in discourse analysis with the other approaches: for instance, the explanation on how we organize language into units beyond sentence boundaries, or how language is used to convey information about the world, ourselves and human relationships (Schiffrin 1994: viii). For other dimensions, each approach holds its distinctive characteristics contributing to the vastness of discourse analysis. This paper will mainly discuss two approaches to discourse analysisconversation analysis and speech act theory- and will attempt to point out some similarities as well as contrasting features between the two approaches, followed by a short reflection on their strengths and weaknesses in the essence of each approach. The organizational and discourse features in the exchanges among three teachers at the College of Finance and Customs in Vietnam will be analysed in terms of conversation analysis and speech act theory.
\end{abstract}

Keywords: Discourse analysis, conversation analysis, speech act theory, discourse features

\section{Introduction}

To begin with, brief definition of the two approaches will be stated as starting point for the whole discussion. Conversation analysis approach to discourse analysis grew from the work of Harvey Sacks, Gail Jefferson and Emanuel Schegloff in the early 1960s. The approach looks at the analysis of natural conversations in order to discover what the linguistic characteristics of conversations are, and how conversations are used in ordinary life (Longman dictionary of Language teaching and Applied linguistics 1992). It emphasizes on the basic forms of everyday spoken interactions in which people exchange information and maintain social relations such as casual conversations, narratives, interviews, interactions at workplace or in classroom, service encounters and so forth ( Paltrige 2000:83). Two philosophers of language- John Austin and John Searle developed Speech Act Theory in the 1950s and 1960s. This approach to discourse looks at how meaning and actions or functions are performed through language (Schiffrin 1994).

According to Paltridge, "Critical discourse analysis explores the connection between the use of language and the social and political contexts in which it occurs."

\section{Common features between Conversation analysis and Speech Act theory}

In terms of their nature and functions to discourse, conversation analysis and speech act theory share some similarities, both view language as 'social interaction' and have the same assumptions about cooperative principles ( Crice's Maxims) and politeness principles.

All approaches to discourse analysis view language as 'social interaction'. Similarly, conversation analysts assume that social interaction is the locus of language use: what we know and understand about interaction accounts for our ability to use language. Likewise, speech act theory puts an emphasis on the linguistic actions that we perform towards another person (Schiffrin 1994:414). The linguistic function of language is to transfer the effect of what the speaker says onto the hearer through interactive activity which involves our sociocultural knowledge in interaction process, and this activity has a' shuttling' effect in which this person's intention has an effect on the other person and a predicted response from the second person will occur towards the first one.

CA and speech act theory also share common assumptions in cooperative and politeness principles. Participants need to apply basic principles which are formulated in a series of maxims: Grice's maxims about cooperative principles- the maxim of quality, quantity, relevance and manner (Cook, 1989:29)- and three maxims of politeness principles suggested by Lakoff-'Don't impose! Give options! and Make your receive feel good!' two systems of principles, to some extent, are in conflict. However, people must follow these principles with full awareness so that they could interpret the utterances of each other. Additionally, for successful communication, participants also need to associate 
with knowledge about the world outside language that speech act theory reflects. In other words, the speaker's illocutionary meaning must be appropriately reasoned and interpreted into pragmatic meaning by the hearer. For example, when someone says 'Goodnight' to another person, the second speaker probably replies 'Goodnight' in return. From the cooperative principles, we assume that the participants are very brief and clear in their utterances of saying goodbye, and obviously, it is relevant that it happens in a true situation of salutation. From the politeness principles and speech act theory assumption, the hearer does not mean that he has to wish a good night to the first speaker just because of polite ness, but his utterance 'Goodnight' here is merely a way to say goodbye. Generally, CA is a full form of speech act theory.

\section{Contrasting points}

All approaches to discourse analysis share the same goal in their functions; however, each holds different views depending on its distinctive functions to discourse. Conversation analysis and speech act theory differ from each other in terms of their different origins leading to a series of different assumptions about linguistic and interactive meanings, the degree of language role in communicative purposes, structures and function direction to discourse, view on 'text' and 'context' and finally, methods of collecting and analyzing data.

\subsection{Different origins}

CA originated from humanistic perspective, whereas speech act theory began from philosophy ( Schiffrin 1994:409401). While the role of speaker's intention and the association across utterances are seriously taken into account by speech act theorist. CA does not put much emphasis on speaker's intention and on the relationship across the utterances like speech act theory. Instead, it focuses on explanation for human behavior- the social and cultural meanings that speaker and hearer exchange in the process of interaction. And if it puts such emphasis, implications about speaker's intention, linguistic meaning or relationship across utterances must be demonstrated in actual circumstances.

\subsection{Linguistic and interactive meanings}

Different origins make CA and speech act theory differentiate in their assumptions about linguistic and interactive meanings, and about the degree of language role in communicative purposes. For this domain, CA strongly goes for communicative meaning. Put another way, in CA, interactive meaning is more important than linguistic or grammatical discussion. In sharp contrast, speech act theory signifies linguistic analysis of text/utterance as the sore function in producing and interpreting utterances. A heavy focus on linguistic competence (i.e. on grammatical usage) accounts for a 'successful' and 'non-defective' performance of an act ( Schiffrin 1994:410).

\subsection{From structure and function dimension}

Another contrasting feature between CA and speech act theory is their opposite view on structure and function in DA. CA begins from structure- a unit of language that is larger than the sentence-and then, leads to function-the use of language in communicative purposes (Shiffrin 1994:339). Starting with this direction, conversation analysts assumes that interaction is structurally produced through patterns in conversations, then, the rules accounting for this structure revealed as the next stage of interaction. An example of this case is adjacency pair- a sequence of two adjacent utterances produced by different speakers and ordered as the first pair part (i.e. 'Congratulations!') and the second pair part (i.e.' Thank you '). Even in turn -taking techniques where conversational participants should be aware of the turntaking rules-when to take turn or when to give turn etc, CA still makes structure more significant than function. On the contrary, units in speech acts theory are sequentially arranged in certain patterns (Schiffrin 1994:346). They are, actually, linguistic devices for language functions such as the illocutionary meaning in a sentence, highlighted by a verb naming the act e.g. pronoun, name, promise etc. one main reason Schiffrin (1994) explains why function is more concerned than structure in speech act theory is that, to know the functional aspect of an utterance, we'd rather investigate the context where that utterance relates to surrounding utterances. To make it clear, consider the different functions of the utterance 'please' in these following examples:

(a) Turn off the light, please!

(b) A: Do you need some help?

B: Please

In (a), the function of 'please' is to emphasize a polite marker of making a request, whereas 'please' in (b) serves as a polite way of accepting an offer. Therefore, the same utterances can produce difference functions depending on the context that it is in.

\subsection{Views on 'text' and 'context'}

To further discuss the contrasting features, we look at how CA and speech act theory view 'text' and 'context', particularly, the aspects of 'text' and 'context' that are pertinent to the production and interpretation of utterances that contribute to communicative content. Before elaborating on this dimension, a brief definition of 'text' and 'context' may simplify our work of identifying the difference. Schiffrin (1994) defines' text' as the linguistic content of utterances. 'Text' provides for the "what is said' part of the utterances, while 'context' combines "what is said" to create an utterance. In the view of context, CA regards context as 'knowledge', 'situation' and 'text'. A distinctive element that CA differs from speech act theory lies in its view of 'knowledge'- a sort of common-sense knowledge that participants in conversation share in constructing talk. At this point, CA views context as 'knowledge'. Still, knowledge 
becomes useful only it is used in specific 'situations' in which participants perform the right action in the right circumstance in the talk. CA, thus, links 'knowledge' to 'situation' (Schiffrin 1994:376-378).

Schiffrin (1994) also proves that in CA, the sequential progression of interaction in which the position of utterances is important. She said that each utterance is formed by a prior context and it also produces a context for a next utterance, and the participants' communicative interaction is contextual in the way of both 'context-shaped' and 'contextrenewing' (Heritage 1984a:242, cited in Schiffrin 1994:378). As here, we can conclude that CA not only views contextas-text but also context-as-knowledge and context-as-situation.

Different from CA, speech act theory regards 'context' merely as' knowledge' of rules and conditions, which help the speaker appropriately to convey his intended acts, and help the hearer to interpret what the speaker actually means. This knowledge is also called 'mutual knowledge', located coherence across utterances, which $\mathrm{Ca}$ finds in behaviour contexts. 'Context', thus, plays a very significant role in production and interpretation of an utterance.

\subsection{Methods of data collection and analysis}

Last of all, although CA and speech act theory get data from a speech community-that is to say, data is taken from people using language, their ways of collecting and analyzing data are quite different. While in CA, as Schiffrin (1994) points out, all aspects related to participants' performance of an utterance are likely to be indicated in "what is said" and "what is done", speech act theorists propose that participants' social, cultural and personal characteristics do not affect their process of constructing talk. Obviously, conversation analysts downplay linguistic form whereas speech act theorists are highly concerned with linguistic functions and meaning. Specifically, data in CA are collected from phenomena, which regularly and systematically occur in the interaction. On this ground, further investigation about analysis of sequential structures and coherence of conversations will be exploited.

\section{Strengths and weaknesses of conversation analysis, speech act theory}

Both CA and speech act theory prove their indispensable significance in discourse analysis. CA makes participants in any spoken interaction aware of conversational techniques e.g. when to take turn or to give turn, how to produce appropriate response, how to give feedback, or how to manage topic etc. Speech act theory helps language user the language for communicative purposes through their linguistic competence. They, for instance, can understand the message beneath the surface of illocutionary force that speaker means so that they can interpret accurately the utterances performed.

Nevertheless, CA and speech act theory have some disadvantages in their contribution to discourse analysis. Schiffrin (1994:232) remarks that CA creates its own assumptions, methodology and its own way of theorizing, which results in the fact that CA, with much freedom, face some obstacles that affect its nature. One of the biggest problems lies in the validity of data. However, the work of data analysis in CA does not include speaker's reflections on interactions e.g. in daily conversations or interviews etc. That way of gathering data as information shows 'idealization' about how interactions work. Therefore, the data are not quite valid for analysis because conversation analysts just look at data alone and explain what is going on in an interaction, not using data-gathering procedures such as interviews, questionnaires and participant observations (Heritage 1984, cited in Paltridge 2000:84-97).

Speech act theory also has its weakness; firstly, it is not distinguishable to realize what is the actual meaning of speaker's utterances because one locutionary act may cause different illocutionary meanings. For example, when we hear someone ask: "Will you join us?" before a party is held, we do not know whether he actually wants us to participate in the party or he just wants to know if we want to go or not. This also accounts for the fact that people form different cultures will encounter difficulty in interpreting the speaker's meaning. Thomas (1983,cited in Paltridge 2000:30-31) describe this failure of conveying or understanding an intended illocutionary force in a second language and culture as two types of cross-cultural pragmatic failure: pragmalinguistic and sociopragmatic failure. Pragmalinguistic failure is none other than failure in linguistic competence where a speaker transfers linguistic meanings of a speech act from their L1 to L2. Sociopragmatic failure arises from the difficulty of understanding the different culture of the target language.

\section{The analysis on the organizational and discourse features in the exchanges that spoken reveals.}

Title: A very first discussion on setting up an English speaking club at the College of Finance and Customs (CFC).

Setting: A group assigned by the school is in charge of setting up an English club. Trang who is a group leader sent email to Ngan and Dinh to announce the date and place where the first discussion will happen. On Sunday morning, they gathered in the college hall at 8:30 a.m. Everyone was on time. Therefore the discussion took place and lasted 30 minutes. The recording also lasted approximately 30 minutes but the defined moment is just 4 minutes long.

Interlocutors: Ngan, Trang, Dinh. All of them are English teachers at CFC

Transcription conventions:

Trang: Hello everyone (.5) today we are going to talk $\uparrow$ about forming an English speaking club in our school (.) First of all, I invite Ms Ngan to talk about the reason why we need that club in our school.

Ngan: Hi (.) as you know an English club will help students to practice speaking English so that their speaking can (be) improved significantly.

Dinh: 0 improved 0 


\section{Trang: That's fantastic $=$}

Ngan: $=$ Well (.) this also a chance for them to relax and make new friends.

Dinh: Yea::h

Trang: Who can tell some criteria $\uparrow$ we need to set it up,

Dinh: Can I say something?

Trang: [Sure] go ahead

Ngan: [Ok:] $=$

Dinh: $=$ Well, we have to own a wide variety $\uparrow$ of topics which are [interesting] first.

Trang:

Ngan is supposed to do that. Is it alright, Ngan?

[interesting] this task I have one person can do.

Ngan: Absolü::tely. I'll do it,

Trang: Go::od job, continue your idea Dinh.

Dinh: Yeah, secondly $(.5)$ we need to get to know the time $=$

Ngan: = May I interrupt. In my opinion, we should hold it twice [a month]

Dinh: twice [a week.]

Ngan: Oh::, \# No \# twice a month?

Trang: twice a month. Give me the reasons?

Ngan: uhm::. Students need more time for their study=

Dinh: = And we need time to prepare everything well, NOW, I got Ngan's point.

Trang: Ok:: so we should hold the speaking at the beginning or at the end of each month. What do you think $\uparrow$, Dinh?

Dinh: $<$ Ah $>$ I think:: On the second and the forth Sunday=

Ngan: $=$ Students are free on the weekend. Good

Trang: That's a goo::d idea (.5) By the way (.) we should talk about the finance. How much we need and where we can get it, Dinh, you have any idea?

Dinh: Uhm:: as far as I know(.5) we need about 50 USD per time o for o the preparation. What do you think $\uparrow$ Ngan?

Ngan : I couldn't agree more but where can get money?

Trang : [school]

Dinh : [School] \# school\#

Trang: I will write the proposal and ask for school (.) anyway

Dinh : Don't write it too late.

Trang : Of course

Ngan: You should do it as soon as possible.

Trang: Yu::p?

Dinh: Can I say something?

Trang : Why not?

Dinh: The thing I really wonder [now who will] be the MC?

Ngan : [what's that?]

Trang : I a::m extremely busy(.5) \# So\#..=

Ngan: $=$ I wish I could,

Dinh : No problem(.) I will find a good student who o can o speak English well=

Ngan: $=$ Furthermore (.5) that student is also enthusiastic +

Trang : $=$ Confident

Ngan : >Confident $<$

Dinh : That's fine?

Trang : At the moment, do you know $\uparrow$ anyone, Dinh?

Dinh : Anyone? Who is anyone? =

Trang : =Do you know any student to help us?

Dinh : Uhm.....uhm.... I don't..

Ngan : Yea::h (.5) I know one student who can do that. That is Long. He is very excellent? very excellent= 
Dinh: = Yeah.(. )He is very good? I know him(.5) What is a smart student!

Trang: Who contacts him?

Ngan: well:....

Dinh: He is my class.

Opening is the first aspect of CA analysis. It is going to be analyzed at first. In the conversation, instead of saying 'how are you?' after a greeting which are popular utterances used in English, Trang is the first person to say " hello" to the rest of two colleagues before she starts the main purpose of the meeting. That is a similar pattern for opening a face to face conversation. After a .5 second pause in Trang's statement, she continues to tell the main topic which is considered as an introduction-also included in the opening. Her utterance introduces the participant named Ngan to raise her voice so that the conversation can be ahead after a falling intonation.

\begin{tabular}{lll}
\hline Turn & speaker & Transcribed text \\
\hline 1 & Trang & $\begin{array}{l}\text { Hello everyone (.5) today we are going to talk } \uparrow \text { about forming an English speaking } \\
\text { club in our school (.) First of all, I invite Ms Ngan to talk about the reason why we } \\
\end{array}$ \\
& need that club in our school. \\
\hline
\end{tabular}

Secondly, Turn taking and turn over can be easily found during the discussion. In this conversation analysis, I also mention and analyze how Trang, Dinh and Ngan take and manage the turns during the discussion. First of all, take Trang's turn in to consideration, after greeting everyone, she nominates Ngan to raise her voice she comes to the end of a turn with the use of falling intonation. Ngan can recognize this signal and she takes the turn in cooperative manner.

\begin{tabular}{lll}
\hline Turn & speaker & Transcribed text \\
\hline 1 & Trang & $\begin{array}{l}\text { Hello everyone (.5) today we are going to talk } \uparrow \text { about forming an English speaking } \\
\text { club in our school (.) First of all, I invite Ms Ngan to talk about the reason why we } \\
\text { need that club in our school. }\end{array}$ \\
\hline 2 & Ngan & $\begin{array}{l}\text { Hi (.) as you know an English club will help students to practice speaking English } \\
\text { so that their speaking can (be) } \underline{\text { improved significantly }}\end{array}$ \\
\hline
\end{tabular}

Trang has taken the conversation away from Ngan when knowing the completion of syntactic unit by saying "That's fantastic." However, Ngan takes her turn back by using latching.

\begin{tabular}{lll}
\hline 4 & Trang & That's $\underline{\text { fantastic }}=$ \\
\hline 5 & Ngan & $=$ Well (.) this also a chance for them to relax and make new friends. \\
\hline
\end{tabular}

Besides that, ending a unit with signal filler ex: anyway lets another speaker make up a turn as in turn 30, Trang ends her turn with "anyway" after a short pause.

\begin{tabular}{lll}
\hline 30 & Trang & I will write the proposal and ask for school(.) anyway \\
\hline
\end{tabular}

After asked to give idea, Ngan replies and ends with a falling intonation that signals listener that her turn is over and allows other one to take the turn.

\begin{tabular}{lll}
\hline 13 & Ngan & Absolu::tely. I'll do it, \\
\hline
\end{tabular}

In turn 39, Trang is reluctant to give the prompt answer that makes Ngan takes a turn and shows her idea that she is in the same shoes as Trang.

One strategy to indicate a turn over signal is by asking a question so that speaker can have the reply from listener.

$7 \quad$ Trang $\quad$ Who can tell some criteria $\uparrow$ we need to set it up,


Speaker speaks the word "criteria" with high pitch to emphasize the point she is mentioning to hold on to a turn.

A listener can even use overlap not only to take a turn from the current speaker but also want to add more information (Paltridge, 2006) here while Dinh is on his turns; Trang overlaps so that the turn can be taken.

\begin{tabular}{lll}
\hline 11 & Dinh & $=$ Well, we have to own a wide variety $\uparrow$ of topics which are [interesting] first. \\
\hline 12 & Trang & $\begin{array}{l}\text { [interesting] This task I have one person can do (.5) Ngan is supposed to do that. Is } \\
\text { it alright, Ngan? }\end{array}$ \\
\hline
\end{tabular}

After speaker has a turn, there is a .5 second pause in her statement, she holds on to a turn so that no one can interrupt. Turn taking can happen when they nominate another speaker so that the conversation may be on its way.

In turn 25, Trang nominates Dinh to give his idea on how much money should be spent.

\begin{tabular}{ccc}
\hline 25 & Trang & $\begin{array}{c}\text { That's a goo::d idea (.5) By the way (.) we should talk about the finance. How } \\
\text { much we need and where we can get it, Dinh, you have any idea? }\end{array}$ \\
\hline
\end{tabular}

Similarly, Dinh is asked to raise his voice, which means that a turn will be taken cooperatively without competition.

Speakers may keep a turn by not pausing too long at the end of an utterance and starting saying something more. Moreover, speaker may hold on a turn by pausing during an utterance and increasing the volume, lengthening vowels or syllables (Paltridge 2006)

In turn 20 Ngan lengthens uhm....to prevent someone taking a turn. Right after that, she continues her statement. In turn 50 Ngan lengthens it again. Moreover, she doesn't pause too long so that she can complete her speaking.

\begin{tabular}{lll}
\hline 20 & Ngan & Uhm::. Students need more time for their study= \\
\hline 50 & Ngan & $\begin{array}{l}\text { Yea::h (.5) I know one student who can do that. That is Long. He is very excellent? } \\
\text { very excellent= }\end{array}$ \\
\hline
\end{tabular}

The next organizational and discourse features in the exchanges that the spoken text reveals are adjacency pairs and preference organization. Adjacency pairs are utterances produced by two successive speakers in a way that the second utterance is identified as related as related to the first one as an expected follow-up to utterance (Paltridge 2006).

Levinson (1983) summarized adjacency pairs in the following way

\begin{tabular}{|c|c|c|c|c|}
\hline \multirow[t]{2}{*}{ First pair part } & \multicolumn{4}{|l|}{ Second pair parts } \\
\hline & Preferred & dispreferred & Likely utterances & \\
\hline Request & Accept & Refuse & Yes okay & No I don't want to \\
\hline Offer/ invite/ give & Accept & Refuse & $\begin{array}{l}\text { Yes I'd be happy } \\
\text { to, thanks }\end{array}$ & No I don't want to \\
\hline Assess & Agree & Disagree & $\begin{array}{l}\text { Oh yes } \\
\text { Thank you } \\
\text { Quite right }\end{array}$ & $\begin{array}{l}\text { No, I don't think } \\
\text { so; I wouldn't } \\
\text { agree }\end{array}$ \\
\hline Question & Expected answer & $\begin{array}{l}\text { Unexpected/ } \\
\text { Non answer }\end{array}$ & Yes & No; why? \\
\hline Blame & Deny & Admit & No, I didn't & Well yes I did \\
\hline Compliment & Accept & Reject & $\begin{array}{l}\text { Oh you really } \\
\text { think so }\end{array}$ & Not important \\
\hline
\end{tabular}

In order to listen to listener's opinions, Trang asks the questions: "who can tell some criteria we need to set it up," and she pauses for the seconds to wait for response from listener. Right away, Dinh replies "Can I say something?" According to the table above by Levinson, the first pair of adjacency pair is request and the second pair part is an accept. So this adjacency pair is preferred. Similarly, when asking if Ngan can be in charge of selecting topics, Trang 
makes a question "Is it alright, Ngan?" An expected answer is followed "Absolutely. I'll do it." Thus, second pair part may be preferred. The same adjacency pairs can be encountered in turn 26 and 27:

Dinh: Uhm:: as far as I know(.5) we need about 50 USD per time o for o the preparation. What do you think $\uparrow$ Ngan?

Ngan : I couldn't agree more but where can get money?

In turn 35, to take a turn Dinh says "can I say something?" he raises his voice to seek the response, "why not?" is then followed and considered as a preferred pair part. However, not only preferred pair parts but also dispreferred ones can be seen in this conversation. For example, in turn 37.

Dinh: The thing I really wonder now who will be the MC?

Trang : I a::m extremely busy(.5) \# So\#..=

As we can see, an refusal appeared after a question by Dinh "I am extremely busy", he means that he couldn't be the MC. So this second part is dispreffered. Moreover, a compliment can be followed be an accept or a reject. In turn 50 and 51 by Ngan and Dinh respectively. When giving compliment on a good student, he says: he is very excellent. The response to this compliment is: yeah, he is very good. Thus, this pair part is an accept, so it is preferred.

Austin (1962) pointed out that the locutionary act; the illocutionary act and the perlocutionary act happen during the conversation. In this conversational analysis, speech acts is also an aspect which appears several times in the face to face discussion. According to Searle, language can be used to show and perform acts. Moreover, making request, giving order, giving warning, challenge, hope and advice can be carried out by using language which is beyond the literal meaning. Locution, illocution and perlocution have the same meaning as the term "speech acts". In turn 31, Dinh says:" the sooner, the better". This is locutionary act.

The illocutionary acts is the understanding of the intended meaning: "will I write the proposal right away?"

The perlocutionary act:" I will write it right away." Trang is supposed to do that.

Also according to Searle, utterances can be devided in to a small set of function including: directive, commissives, representatives, expressives, and declaratives.

In turn 32, speaker speaks out:" of course". This means that she promises to do it. So this is commissive. Besides that, after hearing speaker finishes her turn, the listener takes a turn and goes "that's fantastic", which plays an expressive function. Similarly," what is a smart student" spoken by Dinh in turn 51 is another expressive to give a nice compliment on one student.

Conversational implicature can be inferred from a hearer through speaker's intended meaning. For example, by saying "I wish I could" does not mean that the speaker will do it. The listener will understand the speaker cannot do it and refuse to be in charge of it by inferring the intended meaning.

Pre-empt signals are used politely to interrupt happening communication. The listener can use it as a way to take a turn. In this recorded I found out one pre-empt signal. In order to add more information to Dinh's idea, Ngan starts saying:" may I interrupt" and then she continue her statement after a short pause. It thus shows the ongoing speaker to know that turn is taken.

To give information about success of failure of communication between listener and speaker, back channel is used here. During this discussion, some back channel signals can be recognized easily. All of them are spontaneous and immediate. For example, when listening to sender go: "this also a chance for them to relax and make new friend" the receiver response "yeah". This means that he agrees totally in turn 6.

In communication, make sure that the sender's message is interpreted correctly to avoid the failure in understanding. However, when not hearing the message clearly, there are two trends of repair occur. First of all, the sender will repair himself. Second one, the listener is probably correct the message. Let take turn 48 as an example, Trang asks: do you know any one, Dinh?" the listener promptly replies: anyone? Who?" it shows that he could not catch the meaning and content of the question. To make Dinh understood, Trang corrects herself "do you know any student to help us?" Clearly, listener can get what she said; therefore the communication cannot be broken down.

In conclusion, the recorded, transcribed and annotated conversation above reflected how speakers managed and interacted during the discussion. The discussion has generally been managed through the recognition of transition and maintained in a cooperative manner reflecting Grice's cooperative principle (1975). Moreover, the organizational and discourse feature in the exchanges are revealed in the conversation.

\section{Conclusion}

We discussed two approaches to discourse analysis: conversation analysis, speech act theory on the ground of pointing out their similar aspects as well as their contrasting features. We also made clear their strong points and weak points, which they hold by nature. Each approach, somehow, incorporates the quintessence of language into its assumptions and methods. CA and speech act theory, in fact, are very useful devices for language users to analyze and apply techniques in spoken interactions that they encounter everyday, particularly in educational setting. Teachers study a variety of approaches to discourse, then, helping their learners to have full awareness of conversational techniques or strategies to interpret/ speaker's intention. In sum, all approaches to discourse analysis have their strengths and weaknesses. However, it is creative and challenging for analyst to balance the three ends by making use of the disadvantages of one approach and turning them into advantages of another. 


\section{References}

Brown, G., \&Levison, S (1987). Some universals in language usage. Cambridge : Cambridge University Press.

Cook, G (1989). Discourse Analysis. Oxford University Press.

Hatch, E. (1992). Communication theory: ritual constraints. In Discourse and language education. Cambridge, UK: Cambridge University Press.

Green, M. (1989). Implicature. In Pragmatics and natural language understanding. Hillsdale, NJ: Lawrence Erlbaum Associates.

Grice, H.P (1975),'logic and conversation', in P.Cole and J.L.Morgan (eds), Syntax and Semantics 3: Speech acts. New York: Academic Press. Reprinted in A. Jaworkski and N. Couppland(eds) (1999), The Discourse Reader. London: Routledge, pp. 76-88

Murcia, M and E, Olshtain.200. Discourse and Context in Language Teaching. Cambridge : Cambridge University Press.

Paltridge, B. (2000). Making sense of Discourse analysis. Queensland: Gold Coast. (2006). Discourse Analysis. London: Continuum International Publishing Group.

Schiffrin, D. (1994). Approaches to Discourse. Oxford and Massachusettes: Blackwell Publishers.

Van Dijk, A. (2003). Critical discourse analysis. In D. Schiffrin, D. Tannen, \& E. Hamilton (Eds.), The handbook of discourse analysis. Oxford, UK: Blackwell. 